\title{
Responding to climate change and expectations for research
}

\author{
Hitoshi Kodaira
}

Published online: 18 March 2014

(c) The International Society of Paddy and Water Environment Engineering and Springer Japan 2014

Recent reports have stated that the worsening of global warming may have stopped in the past 15 years.

The rise of the global average surface temperature definitely appears to have paused in the past $10-15$ years, which is inconsistent with the rising trend in past predictions of climate change. On the other hand, the global atmospheric $\mathrm{CO}_{2}$ concentration is continuing to rise and passed $400 \mathrm{ppm}$ last year for the first time in human history. So, the international consensus is that global warming is continuing to progress.

In the real world, disasters caused by extreme weather phenomena are being reported with increasing frequency. Examples include severe drought damage in the Horn of Africa of East Africa and in the Sahel region of West Africa in 2011-2012, an unprecedented decrease in the quantity of ice in the Arctic Sea and Greenland, and largescale long-lasting flood damage in Southeast Asia in 2012. Furthermore, in 2013, record-breaking floods occurred in vast areas of Central Europe and the Amor River basin on the border between China and Russia. Severe climatic events are an increasing risk.

In Japan, in the summer of 2013, 143 places throughout the country witnessed record-high maximum daily temperatures. Shimanto City in Kochi Prefecture, for example, experienced a record-high of $41{ }^{\circ} \mathrm{C}$ on August 12, the highest ever recorded in Japan. Other extreme rainfall events in Japan include record rainfall in parts of the Sanin, North Kinki, and Tohoku regions caused by the stationary seasonal rain front and by typhoons, and an extreme

\section{H. Kodaira ( $\square)$}

The Rural Environment Division, Rural Policy Department, Rural Development Bureau, Ministry of Agriculture, Forestry and Fisheries, 1-2-1, Kasumigaseki, Chiyoda-ku, Tokyo, Japan e-mail: hitoshi_kodaira@nm.maff.go.jp decrease in precipitation in the Southern Kyushu, Amami, and Tokai regions. According to the Meteorological Agency, the direct cause of these extreme conditions was the wide-area circulation of the global atmosphere and the ocean. However, the probable indirect cause is the longterm impact of global warming. Thus, concern about climate change is growing.

All parties to the UNFCCC have been conducting international negotiations toward establishing a new legally binding framework to achieve ambitious GHG reduction targets by 2020. Since last autumn, the IPCC has published a series of AR5 which present the latest knowledge concerning climate change impacts such as global warming and projections based on scientific evidence.

In its 2007 report, AR4, the IPCC stated that the increase in global average temperatures was very likely $(90 \%$ probability) due to the observed increase in anthropogenic GHG concentrations and warned that the impact of climate change would be unavoidable in the coming decades. This triggered growing awareness of the importance of reducing GHG (mitigation measure) thought to directly cause climate change, and reducing or mitigating unavoidable future climate change impacts (adaptation measures), throughout the world and Japan. In some fields, detailed studies and concrete efforts have already commenced. The latest AR5 confirms that future global warming is increasingly certain to occur, and more must be done to prepare for this.

In Japan, measures to adapt to global warming have been advocated. The Fourth Basic Environment Plan (2012) urges that urgent adaptation measures be taken to prevent or mitigate the short-term climate impact, and that studies be conducted on raising our ability to prevent or mitigate the mid- to long-term climatic impacts. Under the MAFF strategy for countermeasures against global 
warming (2008), measures for monitoring and evaluating climatic impact on a large scale over broad agricultural areas of the country must be studied in order to maintain prime farmland in the future, as well as to evaluate the impact of future climate change on Japan's agricultural production base, and to study necessary adaptation measures and methods of implementing these measures. The latest "Land Improvement Long-term Plan" (2012) recognizes the importance and necessity of responding to climate change including global warming, and as responses to global environmental issues, it includes the study of concrete adaptation measures for the near future, the application of new technologies, and their reflection in land improvement facilities management criteria, while continuing to predict and evaluate the mid- and long-term impact of climate change on farmland and the agricultural production base.

However, it is difficult to precisely predict future global climate change, because of the difficulty of isolating the impact of slight mid- and long-term climate change including global warming from various factors impacting the global environment, the uncertainty of future climate change projections under hypothetical future scenarios, incomplete understanding of the factors causing global climate change, and so on. Furthermore, we face many challenges in actually addressing land improvement facilities in each area, where climate conditions differ greatly, due to the severe uncertainties of future projections.

For this reason, it is important to make further efforts to understand the factors and attributions of future global climate change to continuously improve the precision of climate projections by collecting and analyzing climate data and applying the scientific knowledge obtained. Therefore, experimental research has a crucial role to play.

We have high expectations for this research, and hope to link with social communications including the proposal of adaptation measures based on the research outcomes.

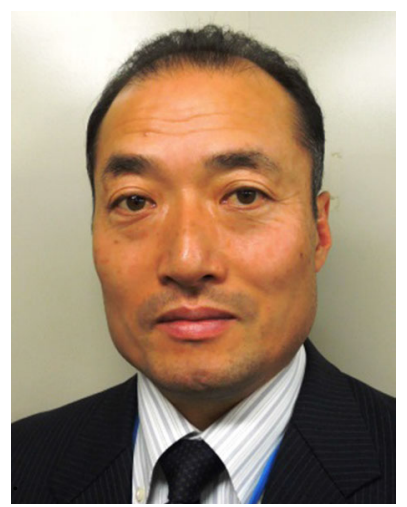

Hitoshi Kodaira is the director of the Rural Environment Division, Rural Policy Department, Rural Development Bureau, Ministry of Agriculture, Forestry and Fisheries, Japan. The Rural Environmental Division plans and enacts surveys and conducts studies to enact plan criteria and to commercialize new technology to conserve the environments of agricultural production base in rural areas 